\title{
Ethical Portfolio Theory: A New Course
}

\author{
Carla Barracchini ${ }^{1} \&$ Maria Elena Addessi ${ }^{2}$ \\ ${ }^{1}$ Department of Systems and Institutions for Economics, Università degli Studi di L’Aquila L'Aquila, L'Aquila, \\ Italy \\ ${ }^{2}$ Department of Economics and Politics and Modern Languages, Libera Università degli Studi Maria SS Assunta \\ (LUMSA), Rome, Italy \\ Correspondence: Carla Barracchini, Dept. of Systems and Institutions for Economics, Università degli Studi di \\ L’Aquila L’Aquila, L'Aquila, Italy. E-mail: carla.barracchini@ec.univaq.it
}

Received: March 7, 2012 Accepted: March 28, 2012 Online Published: May 24, 2012

doi:10.5539/jms.v2n2p35 URL: http://dx.doi.org/10.5539/jms.v2n2p35

\begin{abstract}
This paper aims at proposing a re-reading of the Portfolio Selection by means of an extension of the risk/return analysis, thus taking into account the investors' choice that meets the ethical principles of an individual. We aim at describing the portfolio selection realized on the basis of the static ethical index (Barracchini, 2007). We also aim at presenting a dynamic ethical index by the definition of those functions we will call ethical reputation and ethical coherence.
\end{abstract}

Keywords: portfolio theory, ethical finance, Sustainable Responsible Investment (SRI), ethical coherence, ethical reputation, optimization

\section{Introduction}

The wealth of a market economy implies that the different ethical identities of families, enterprises and banks have to be crossed, in order to improve the allocation of resources for a sustainable development. The transparency, for the socially-responsible products market, is still weak and confusion between screened business and humanitarian business is still strong. The difference between ethical business and humanitarian business is fundamental. Ethical business invests in companies with an ethical purpose, an ethical activity, an ethical management. To be considered socially-responsible, a company should have all these characteristics. Humanitarian business, also known as devolution business, implies that investors give up a part or all of their profit to community or solidarity activities.

Humanitarian business cannot be considered ethical because, in the predominant opinion, it is just an indirect form of donation that does not give investors responsibility on how money is used in the investment process (Barracchini, 2007). Evidence from psychology, game theory, anthropology and contingent valuation surveys reveals a more complex pattern of decision-making than that described by neoclassical utility theory. While ethics and utility maximisation in economics seem mutually exclusive, ethics has recently become a crucial issue in financial markets.

The market demand for ethical investment is increasing, suggesting that investment decision are influenced both by financial and moral considerations. Therefore, marketing strategies for ethical investment are needed. (Hopmann-Pesti-Kirchler, 2007). In Jessen (2009), it is shown how superior investment opportunities can emerge when the new dimension is incorporated into the investment decision. The model by Jessen for an optimal responsible investment is considered if structured products may facilitate retail SRI.

Drut (2010) explores the implications of social responsibility in accordance with the model designed by Markovitz, always dealing with such issue at the mean-variance level.

In Barracchini (2007), a model for optimal responsible investment allowing for a personal-value based decision - called ethical index $\eta^{(k)}$ of investor $k^{- \text {th }}$, which we define static - has been shown.

This paper aims at proposing an extension of the static ethical index by means of a dynamic ethical index as well as the definition of the functions of ethical reputation and ethical coherence. In this paper, when the concept of ethical portfolio is used, we mean a portfolio only made of ethical assets. The investor $k^{\text {th }}$ selects such assets as far as a satisfying value of the ethical index $\eta^{(k)}$ will be achieved. The first part of this paper offers a 
definition of the concept of the dynamic ethical index by means of the functions of ethical reputation and ethical coherence. The second part describes the three-dimensional model of portfolio optimization: portfolio risk, expected return and ethical coherence. The third part presents the criteria of selecting a portfolio through a function of "generalized" utility.

\section{Portfolio Selection and Ethical Coherence: A Background}

The mean-variance model (Markowitz, H. M., 1952) regarding the portfolio choices is based on some simplifying hypothesis, such as the investments' one-period term, the absence of taxes and transition costs as well as the perfect competitiveness of the financial markets - that is, a perfect information symmetry,

Let $B_{i}, i=1,2, \ldots, N$ be the $\mathrm{N}$-titles or investments or business;

$x_{i}=$ the quotas of the $i^{-t h}$ title, so that $x_{1}+x_{2}+\ldots+x_{N}=1$

$\tilde{R}_{i}(i=1,2, \ldots, N)$ : the stochastic return of the investment $i^{- \text {th }}$

$\mu_{i}(i=1,2, \ldots, N)$ : the expected return of the investment $i^{- \text {th }}$

$\sigma_{i j}$ : the covariance of $\widetilde{R}_{i}$ and $\widetilde{R}_{j} \quad(i, j=1,2, \ldots, N)$

$\rho_{i j} \in[-1,1]$ : the correlation coefficient

$\widetilde{R}=x_{1} \widetilde{R}_{1}+x_{2} \widetilde{R}_{2}+\ldots+x_{N} \widetilde{R}_{N}$ : the stochastic return of the portfolio

$\mu=E(\tilde{R})=x_{1} \mu_{1}+x_{2} \mu_{2}+\ldots+x_{N} \mu_{N}$ : the expected return of the portfolio,

$\sigma^{2}(\tilde{R})=\operatorname{Var}(\tilde{R})=\sum_{j=1 i=1}^{N} \sum_{i}^{N} x_{i} \sigma_{i j}$ : the variance,

To properly develop the present work, we now need draw on the definition of subjective qualitative index (Barracchini, 2007):

The ethical index of portfolio, $\eta^{(k)}$, is a subjective qualitative index, referring to the qualitative features of investments and whose value, whether not negative, is referred to the ethical preferences of the investor $k^{-t h}$.

This paper aims at examining the ethical improvement or worsening (Note 1) of each asset in the portfolio as time changes. The index $\eta^{(k)}=\eta^{(k)}(0)$ indicates the static ethical nature of the portfolio - that is, the ethical value assigned to the portfolio by the investor $k^{\text {th }}$ in the period of resource investment $t=0$. In a moment subsequent or prior to $\mathrm{t}=0$, the investor $k^{-t h}$ may also assign a different value within the ethical index to the portfolio, without changing the adopted criteria of ethical selection.

Remark: The following procedure, with proper changes, can be extended to the evaluation of the ethical firms and to the control of the ethicality of the firms (Annibali - Barracchini - Bellini, 2008).

The need for a dynamic evaluation of the index $\eta^{(k)}$ is therefore clear. The time function of the index $\eta^{(k)}(t)$ is a safe but not optimal tool, since a customer susceptible to ethics may also reward the attention payed over time by a firm to the respect for ethical principles- that is, the so called "historical ethicality".

In order to measure such historical ethicality, a function hereinafter called ethical coherence needs to be used that is, a function that weighs the dynamic ethicality $\eta^{(k)}(t)$ at any one instant.

In order to define the function of ethical coherence - indicated with $\mathrm{E}^{(k)}(T)$, where $\mathrm{T}$ is the extent of the observation interval of an asset from -T to 0 - introducing a weight, $f^{(k)}(t)$, hereinafter called ethical reputation, is needed.

Thus, the function of ethical coherence is defined as follows:

$$
E^{(k)}(T)=\left\{\begin{array}{lll}
\eta^{(k)}(0)=\eta^{(k)} & \text { if } & t=0 \\
\frac{1}{T} \int_{-T}^{0} \eta^{(k)}(t) \cdot f^{(k)}(t) d t & \text { if } & t>0
\end{array}\right.
$$

Suppose that the ethical reputation $f^{(k)}(t)$ is a monotonically non-decreasing function so that the farthest ethical index $\eta^{(k)}(t)$ does not have a greater incidence than the latest ethical index.

Axiomatic features of the ethical coherence: $\mathrm{E}^{(k)}(t), \quad t \in[-T, 0]$

1) $0 \leq \mathrm{E}^{(k)}(t) \leq 1$

2) $\mathrm{E}^{(k)}(t)=1$ if $\eta^{(k)}(t)=1, \forall t \in[-T, 0]$

Thus, we indicate with 
$E_{i}^{(k)}(T)=E_{i}^{(k)}$ the ethical coherence assigned by the individual $k^{-t h}$ to the business $B_{i}$ in $[-T, 0]$, while the portfolio ethical coherence referring to the individual $k^{- \text {th }}$ in $[-T, 0]$ is the following

$$
E^{(k)}(T)=\sum_{i=1}^{N} E_{i}^{(k)} x_{i}
$$

\section{A Three-Dimensional Model of Portfolio Optimization}

This section presents a three-dimensional model of portfolio optimization: portfolio risk, expected return and ethical coherence.

In this paper we are going to assume portfolio sets of ethical assets that ensure a minimum risk for a fixed return and a fixed level of ethical coherence, observed for all the assets in the portfolio over the same time interval.

In the building up of such a portfolio, the selection of the ethical assets is made according to the ethical coherence observed over a span of time $\mathrm{T}$ prior to the portfolio building-up time $\mathrm{t}=0$.

Such coherence index, indicated with $E^{(k)}(T)$, is assumed to be fixed on a level $\bar{\eta}^{(k)}$.

\subsection{The Case of Three Risky Assets}

In this section we wish to investigate a portfolio whose assets are characterized by two objective and quantitative parameters (the expected return and the riskyness) and a subjective parameter, all of them linked to the asset's quality - that is, the ethical coherence as it has been measured by the individual $k^{\text {th }}$. The portfolio take into consideration holds three types of assets, characterized by the following sets of values: $B_{1}=\left(\mu_{1}, \sigma_{1}, E_{1}^{(k)}\right)$, $B_{2}=\left(\mu_{2}, \sigma_{2}, E_{2}^{(k)}\right), B_{3}=\left(\mu_{3}, \sigma_{3}, E_{3}^{(k)}\right)$

$$
\left\{\begin{array}{l}
1=x_{1}+x_{2}+x_{3} \\
\mu=\mu_{1} x_{1}+\mu_{2} x_{2}+\mu_{3} x_{3} \\
E^{(k)}=E_{1}^{(k)} x_{1}+E_{2}^{(k)} x_{2}+E_{3}^{(k)} x_{3} \\
\sigma^{2}=\sigma_{1}^{2} x_{1}^{2}+\sigma_{2}^{2} x_{2}^{2}+\sigma_{3}^{2} x_{3}^{2}+2 x_{1} x_{2} \sigma_{1,2}+2 x_{1} x_{3} \sigma_{1,3}+2 x_{2} x_{3} \sigma_{2,3}
\end{array}\right.
$$

Supposing $\mu_{i} \neq \mu_{j}$, at least for a value of $i \neq j$ with $i, j=1,2,3$, the set of linear equations made of the first three equations of (3) allows, as regards the unknowns $\left(x_{1}, x_{2}, x_{3}\right)$, a unique solution as described below:

$$
\begin{gathered}
x_{1}=\frac{E^{(k)}\left(\mu_{2}-\mu_{3}\right)-\mu\left(E_{2}^{(k)}-E_{3}^{(k)}\right)}{E_{1}^{(k)}\left(\mu_{2}-\mu_{3}\right)+E_{2}^{(k)}\left(\mu_{3}-\mu_{1}\right)+E_{3}^{(k)}\left(\mu_{1}-\mu_{2}\right)}=\frac{E^{(k)} \Delta^{\mu}(2,3)-\mu \Delta^{E}(2,3)}{E_{1}^{(k)} \Delta^{\mu}(2,3)+E_{2}^{(k)} \Delta^{\mu}(3,1)+E_{3}^{(k)} \Delta^{\mu}(1,2)} \\
x_{2}=\frac{\mu \Delta^{E}(1,3)-E^{(k)} \Delta^{\mu}(1,3)}{E_{1}^{(k)} \Delta^{\mu}(2,3)+E_{2}{ }^{(k)} \Delta^{\mu}(3,1)+E_{3}{ }^{(k)} \Delta^{\mu}(1,2)} \\
x_{3}=\frac{E^{(k)} \Delta^{\mu}(1,2)-\mu \Delta^{E}(1,2)}{E_{1}^{(k)} \Delta^{\mu}(2,3)+E_{2}{ }^{(k)} \Delta^{\mu}(3,1)+E_{3}{ }^{(k)} \Delta^{\mu}(1,2)}
\end{gathered}
$$

Where: $\mu_{i}-\mu_{j}=\Delta^{\mu}(i, j)$ and $E_{i}^{(k)}-E_{j}^{(k)}=\Delta^{E}(i, j)$

In the following equation of variance

$$
\sigma^{2}=x_{1}^{2} \sigma_{1}^{2}+x_{2}^{2} \sigma_{2}^{2}+x_{3}^{2} \sigma_{3}^{2}+2 x_{1} x_{2} \sigma_{1,2}+2 x_{1} x_{3} \sigma_{1,3}+2 x_{2} x_{3} \sigma_{2,3}
$$

if we change the variables $x_{1}, x_{2}, x_{3}$ and write it in a compact way, it follows that

$$
\sigma^{2}=\frac{\sum_{\substack{k, j, j=1 \\ i \neq j \neq k}}^{3}\left[E^{(k)} \Delta^{\mu}(i, j)-\mu \Delta^{E}(i, j)\right]^{2} \sigma_{k}^{2}+2 \sum_{\substack{k, i, j=1 \\ i \neq j \neq k}}^{3}\left(\left[E^{(k)} \Delta^{\mu}(i, j)-\mu \Delta^{E}(i, j)\right] \cdot\left[\mu \Delta^{E}(k, j)-E^{(k)} \Delta^{\mu}(k, j)\right] \cdot \sigma_{k, i}\right)}{\left(E_{1}{ }^{(k)} \Delta^{\mu}(2,3)+E_{2}{ }^{(k)} \Delta^{\mu}(3,1)+E_{3}{ }^{(k)} \Delta^{\mu}(1,2)\right)^{2}}
$$

The equation (5) depends on the expected return and the ethical coherence of a portfolio made of three risky assets.

Remark: In the case of $n>2$ risky assets (e.g., $n=4$ ), the previous case can be followed, thus building up two portfolios made of two assets and examining the resulting portfolio.

In order to analyze the indifference curves of a rational and susceptible-to-ethics individual, we can distinguish among three different subcases on the reference level with a fixed variance, thus carrying on with the examination of the curve (5). In our model we have supposed that the asset $B_{3}$ is risk-free, while the assets $B_{1}$ and $B_{2}$ are 
risky - therefore, $\sigma_{3}=0$ from which $\sigma_{1} \sigma_{3}=\sigma_{2} \sigma_{3}=0$.

Indicating with $\rho_{12}=\frac{\sigma_{1} \sigma_{2}}{\sigma_{12}}$ the correlation coefficient of the two risky assets, we obtain the representation of the possible levels of $\sigma^{2}$, as $\mu$ and $E^{(k)}$ change. The parts in the first quadrant of the chart hold our interest, as for all the cases taken into consideration. A careful-with-ethics customer will never choose a product with negative ethical coherence, as well as a rational customer will never choose an asset with a negative return. If the correlation coefficient $\rho_{12}$ lies between $(-1,1)$, the indifference curves are, compared to the previously fixed $\sigma^{2}$ and as $E^{(k)}$ and $\mu$ change, ellipses whose axes of symmetry are not parallel to the coordinate axes.

It is clear that the Pareto efficiency, where $-1<\rho_{12}<1$, is unique as well as it is the point of intersection of the tangent line to the ellipse and at right angles to the axis crossing the two foci (Table 1 ).

Table 1. Iso-variance curve as a function of correlation coefficient

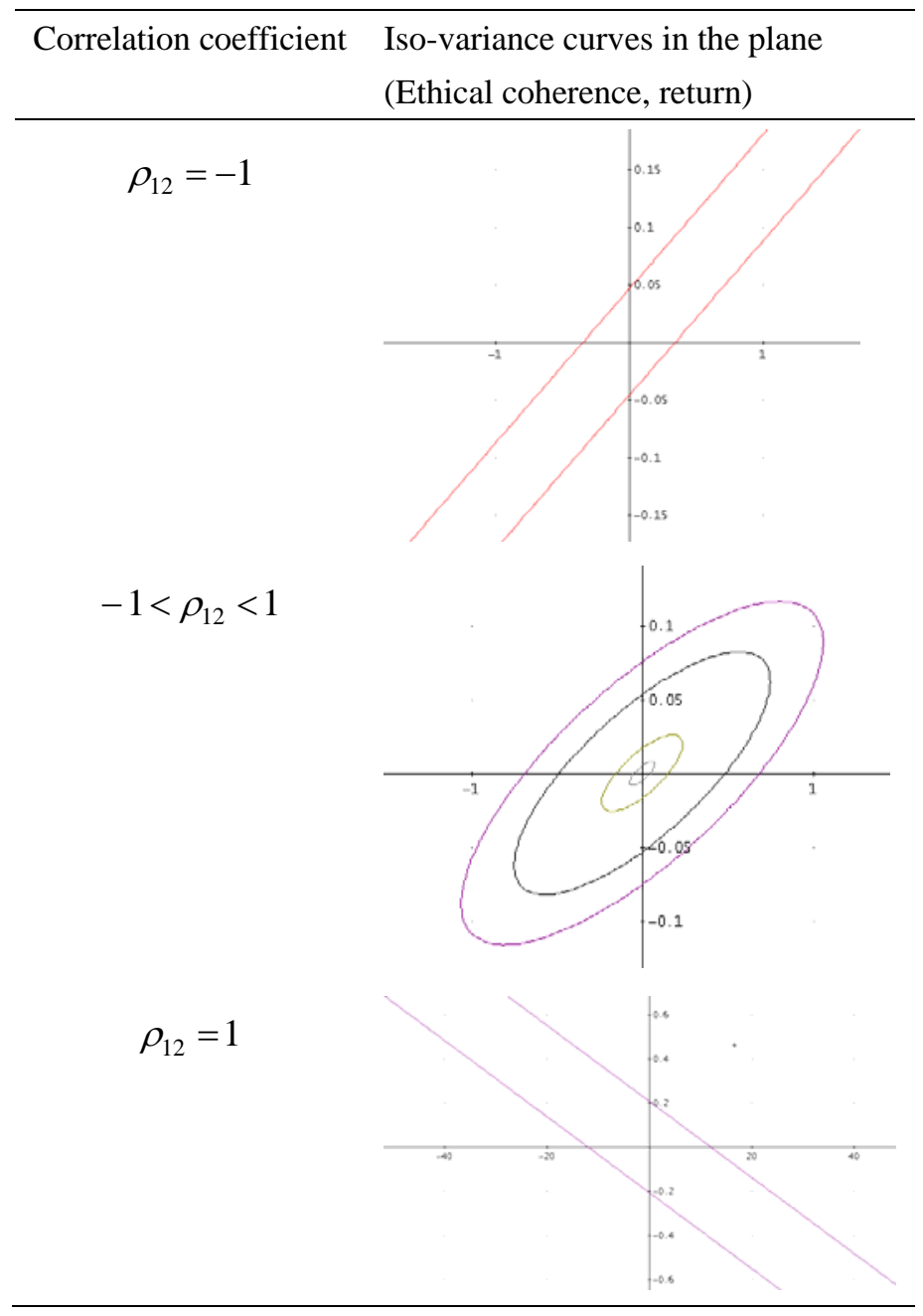

\subsection{The Case of N Risky Assets and a Risk-Free One}

In a more general case of $\mathrm{N}$ risky assets and a risk-free one (the latter indicated with $B_{0}=\left(\mu_{0}, E_{0}^{(k)}, 0\right)$ ), the model becomes:

$$
\left\{\begin{array}{l}
1=\sum_{j=0}^{N} x_{j} \\
\mu=\sum_{j=0}^{N} \mu_{j} x_{j} \\
E^{(k)}=\sum_{j=0}^{N} E_{j}^{(k)} x_{j} \\
\sigma^{2}=\sum_{j=1}^{N} \sum_{i=1}^{N} x_{j} x_{i} \sigma_{j, i}
\end{array}\right.
$$


In order to calculate a portfolio with a minimum variance and once assigned both $E^{(k)}$ and $\mu$, the Lagrangian will be used:

$$
L\left(x_{0}, x_{1}, \cdots ; x_{n}, \lambda_{1}, \lambda_{2}, \lambda_{3}\right)=\sum_{j=i=1}^{N N} x_{j} x_{i} \sigma_{i j}+\lambda_{1}\left(1-\sum_{j=0}^{N} x_{j}\right)+\lambda_{2}\left(\mu-\sum_{j=0}^{N} \mu_{j} x_{j}\right)+\lambda_{3}\left(E^{k)}-\sum_{j=0}^{N} E_{j}^{(k)} x_{j}\right)
$$

The system of partial derivatives in the Lagrangian, setting the constraint that it equals zero, is

$$
\left\{\begin{array}{l}
\frac{\partial L}{\partial x_{0}}=-\lambda_{1}-\lambda_{2} \mu_{0}-\lambda_{3} E_{0}^{(k)}=0 \\
\frac{\partial L}{\partial x_{1}}=2 x_{1} \sigma_{1,1}+\cdots+2 x_{i} \sigma_{1, i}+\cdots+2 x_{n} \sigma_{1, n}-\lambda_{1}-\lambda_{2} \mu_{1}-\lambda_{3} E_{1}^{(k)}=0 \\
\quad \vdots \\
\frac{\partial L}{\partial x_{i}}=2 x_{1} \sigma_{i, 1}+\cdots+2 x_{i} \sigma_{i, i}+\cdots+2 x_{n} \sigma_{i, n}-\lambda_{1}-\lambda_{2} \mu_{i}-\lambda_{3} E_{i}^{(k)}=0 \\
\quad \vdots \\
\frac{\partial L}{\partial x_{n}}=2 x_{1} \sigma_{n, 1}+\cdots+2 x_{i} \sigma_{n, i}+\cdots+2 x_{n} \sigma_{n, n}-\lambda_{1}-\lambda_{2} \mu_{n}-\lambda_{3} E_{n}^{(k)}=0 \\
\frac{\partial L}{\partial \lambda_{1}}=-x_{0}-x_{1}+\cdots-x_{i}+\cdots-x_{n}=-1 \\
\frac{\partial L}{\partial \lambda_{2}}=-x_{0} \mu_{0}-x_{1} \mu_{1}+\cdots-x_{i} \mu_{i}+\cdots-x_{n} \mu_{n}=-\mu \\
\frac{\partial L}{\partial \lambda_{3}}=-x_{0} E_{0}^{(k)}-x_{1} E_{1}^{(k)}+\cdots-x_{i} E_{i}^{(k)}+\cdots-x_{n} E_{n}^{(k)}=-E^{(k)}
\end{array}\right.
$$

Assuming that the vector is not a linear combination of, the previous model can be rewritten as follows:

$$
\left[\begin{array}{cllllllll}
0 & 0 & \cdots & 0 & \cdots & 0 & -1 & -1 & -1 \\
0 & 2 \sigma_{1,1} & \cdots & 2 \sigma_{1, i} & \cdots & 2 \sigma_{1, n} & -1 & -\mu_{1} & -E_{1}^{(k)} \\
0 & \vdots & \cdots & \vdots & \cdots & \vdots & \vdots & \vdots & \vdots \\
0 & 2 \sigma_{i, 1} & \cdots & 2 \sigma_{i, i} & \cdots & 2 \sigma_{i, n} & -1 & -\mu_{i} & -E_{i}^{(k)} \\
\vdots & \vdots & \cdots & \vdots & \cdots & \vdots & \vdots & \vdots & \vdots \\
0 & 2 \sigma_{n, 1} & \cdots & 2 \sigma_{n, i} & \cdots & 2 \sigma_{n, n} & -1 & -\mu_{n} & -E_{n}^{(k)} \\
-1 & -1 & \cdots & -1 & \cdots & -1 & 0 & 0 & 0 \\
-\mu_{0} & -\mu_{1} & \cdots & -\mu_{i} & \cdots & -\mu_{n} & 0 & 0 & 0 \\
-E_{0}^{(k)} & -E_{1}^{(k)} & \cdots & -E_{i}^{(k)} & \cdots & -E_{n}^{(k)} & 0 & 0 & 0
\end{array}\right] \cdot\left[\begin{array}{c}
x_{0} \\
x_{1} \\
\vdots \\
x_{i} \\
\vdots \\
x_{n} \\
\lambda_{1} \\
\lambda_{2} \\
\lambda_{3}
\end{array}\right]=\left[\begin{array}{c}
0 \\
0 \\
\vdots \\
0 \\
\vdots \\
0 \\
-1 \\
-\mu \\
-E^{(k)}
\end{array}\right]
$$

Otherwise, it can also have the following compact structure:

$$
C \cdot \vec{x}=\vec{s}
$$

Such a solution is derived by means of a pre-multiplication of both the members for the inverse of the matrix of $C$ coefficients (we are dealing with a $\mathrm{N}+4$-class, non-singular, square matrix, since it is the extension of the liability of two risky assets and a risk-free one to the case of $\mathrm{N}$ risky assets and a risk-free one):

$$
\vec{x}=C^{-1} \cdot \vec{s}
$$

The same calculation has to be repeated for each value of $\mu$ and $E^{(k)}$ in order to get the optimal combination for an ethical portfolio. In fact, the combination risk-return-ethical coherence makes the curves $\sigma^{2}$ to be constant on the return-ethical coherence level in relation to $\mathrm{N}$ risky ethical assets and a risk-free one.

The Lagrangian has a minimum point only: therefore, the optimal portfolio regarding the variance $\sigma^{2}$ can be observed for each fixed level of $\mu$ and $E^{(k)}$ with $E^{(k)} \geq \bar{\eta}^{(k)} \in(0,1]$.

\subsection{Portfolio Selection Criteria}

According to the traditional theories of portfolio, adopting a standard in order to choose among the various opportunities provided seems to be necessary. For this purpose, the function of utility has to be introduced in 
order to describe the three types of attitudes that an individual may have towards a risky situation: in fact, a person is said to be risk-avoinding, risk-neutral and risk-seeking.

As regards the case provided by our model, it seems to be also necessary to extend the utility function that, therefore, is made of three variables. The case taken into consideration concerns portfolios made of ethical assets only, since they have been selected by rational and susceptible-to-ethics individuals - hence the utility function we have examined is made of the three variables $\mu, E^{(k)}$ and $\sigma^{2}$ :

having the following features:

$$
U\left(\mu, E^{(k)}, \sigma^{2}\right)
$$

increasing compared to $\mu$ and $E^{(k)}$, decreasing compared to $\sigma^{2}$;

therefore, if it is derivable, with

$$
\frac{\partial U}{\partial \mu}>0 \quad \frac{\partial U}{\partial E^{(k)}}>0 \quad \frac{\partial U}{\partial \sigma^{2}}<0
$$

According to the traditional theory of the expected utility (Von Neumann, J., \& Morgenstern, O. 1944), a quadratic form with three variables can be obtained. In case of a non susceptible-to-ethics individual, the parameter is not taken into consideration, thus applying the traditional theory of the risk-return utility.

As the theory of the expected utility has been aware of (subjective but summarized in three categories against indifferent and willing to risk) to risk so, in our opinion, must take into account the ethical sensitivity of the investor.

\section{Final Remarks}

We think that the Portfolio Theory can be re-read, taking into account the attention payed by investors to the quality of business in their choices.

The present study aims at being an attempt - already announced in Barracchini (2007) and Annibali-Barracchini-Bellini (2008) - to provide for a new approach to the portfolio theory.

The cases we have examined ( 3 and $\mathrm{N}$ assets) show that choosing ethical assets only in a portfolio, in accordance with the individual $k^{-t h}$ 's value of ethical coherence, limited the basket but satisfied the investor's moral demands. The use of ethical coherence as a new variable raised the number of equations, thus giving the issue a newly acquired tree-dimensional feature (mean-variance-ethical coherence) rather than the previous bi-dimensional one (mean-variance). Such third dimension increased the complexity of the utility function as well, since an investor also cares about maximizing the portfolio's ethical coherence as well as about rationally operating on return and risk. The outcome of this work has been to determine an efficient frontier from which a unique, optimal, ethical portfolio with a fixed variance can be extrapolated, thus maximizing both the return and the ethical coherence. The uniqueness of such a portfolio does not concern the assets' make-up but the uniqueness itself of the index variables - that is, return and ethical coherence.

Corporate reputation [Fombrun-Rindova (1998), Fombrun-Shanley (1990), Fombrun-Van Riel (1998), Davis (2003)] can be measured by evaluating the solvency and the ability of a company to meet an investor's demand. All the works available on the matter are, in most cases, accounting and empirical models. On the contrary, our proposal concerns the selection of an ethical portfolio - i.e., a portfolio which respects those principles the consumer believes to be consistent with his/her ethics.

We have deeply dealt with the problem of how to quantify an "ethical portfolio size" within a dynamic algorithm as well as how to use such size in the portfolio selection criteria.

The outcome of this work is the introduction of the ethical size as a third dimension in the same way as return and risk in mean-variance method, thus becoming a three-dimensional mean-variance-ethics model.

Our innovative contribution was to establish the conditions for a process of dynamic building-up of the ethical dimension through the definition of the qualitative/quantitative corporate variables - called ethical reputation and ethical coherence respectively.

Thus, a portfolio of $\mathrm{N}$ risky assets and a risk-free portfolio were analyzed, calculating the optimal quantities with a fixed variance at an ethics/return level. In particular, in the case of three risky assets, curves with a constant variance have been represented (see table 1) and the different geometries depending on the correlation coefficient have been shown. Moreover, in the case of three titles, explicit solutions about the weights for each asset in the portfolio (4) have been found. 


\section{References}

Annibali A., Barracchini C., \& Bellini A. (2008). General Evaluation Model for Sustainable Business Certification. Proceedings of the Annual London Conference on Money, Economy and Management, 3-4, July, 2008. Imperial College, London, UK.

Barracchini C. (2007). An Ethical investments evaluation for portfolio selection. Journal of Business Ethics and Organization Studies, 9(1).

Basak, G., Jagannathan, R., \& Sun, G. (2002). A direct test of mean-variance efficiency of a portfolio. Journal of Economic Dynamics and Control, 26, 1195-1215. http://dx.doi.org/10.1016/S0165-1889(01)00044-6

Beltratti, A. (2005). Capital market equilibrium with externalities, production and heterogeneous agents. Journal of Banking and Finance, 29.

Best, M., \& Grauer, R. (1990). The efficient set mathematics when mean-variance problems are subject to general linear constraints. Journal of Economics and Business, 42, 105-120. http://dx.doi.org/10.1016/0148-6195(90)90027-A

Brigham, E. F., \& Ehrhardt, M. C. (2005). Financial Management: Theory and Practice (11th ed.). Southwestern Thomas Corporation.

Cheffers, M., \& Pakaluk, M. (2007). Understanding Accounting Ethics. Allen David Press, Sutton, MA.

Drut, B. (2011). Social responsibility and mean-variance portfolio selection.

Dupré, D., Gired-Potin, I., \& Kassoua, R. (2004). Adding an ethical dimension to portfolio management. Finance India, XVIII (Special Issue), 625-641.

European Sustainable Investment Forum. (2008). European SRI Study. European Sustainable Investment Forum, Paris. Retrieved from http://www.eurosif.org/publications/sri_studies

Eurosif (European Sustainable and Responsible Investment Forum). (2003). Socially responsible investment among European institutional investors. Retrieved from http://www.esorif.org/publications/sri_studies

Eurosif. (2007) .Venture capital for sustainability. Retrieved from www.eurosif.org

Eurosif. (2008a). European SRI studies 2008. Retrieved from www.eurosif.org

Eurosif. (2008b). High Net Worth individuals and sustainable investment. Retrieved from www.eurosif.org

Fombrun C. J., \& Rindova V. P. (1998). Reputation Management in Global 1000 Firms: a Benchmarking Study. Corporate Reputation Review, 1(3). http://dx.doi.org/10.1057/palgrave.crr.1540044

Fombrun C. J., \& Shanley M. (1990). What's in a Name? Reputation Building and Corporate Strategy. Academy of Management Journal, 2.

Fombrun C. J., \& Van Riel C. B. M. (1998). The Reputational Landscape. Corporate Reputation Review, 1(1).

Francis T. Edum-Fotwe \& Andrew D. F. Price. (2009). A social ontology for appraising sustainability of construction projects and developments. International Journal of Project Management, 27(4), 313-322. http://dx.doi.org/10.1016/j.ijproman.2008.04.003

Helgadóttir, H. (2008). The ethical dimension of project management. International Journal of Project Management, 26(7), 743-748. http://dx.doi.org/10.1016/j.ijproman.2007.11.002

Hofmann, E., Meier-Pesti, K., \& Kirchler, E. (2007). The decision process for ethical investment. Journal of Financial Services Marketing, 12, 4-16. http://dx.doi.org/10.1057/palgrave.fsm.4760057

Jennings, M. M. (2005). Ethics and Investment Management: True Reform. Financial Analysts Journal, 61(3), 45-58. http://dx.doi.org/10.2469/faj.v61.n3.2727

Jessen, P. (2009). Structured Products for Sustainable and Responsible Investment. Working paper Aarhus School of Business University Denmark PRI Academic Conference October 3, 2009 Ottawa.

Maio, E. (2003). Managing Brand in the New Stakeholder Environment. Journal of Business Ethics, 44.

Markowitz, H. M. (1952). The utility of wealth. Journal of Political Economy, 60(2), 151-158. http://dx.doi.org/10.1086/257177

Markowitz, H. M. (1959). Portfolio Selection: Efficient Diversification of Investments. John Wiley \&Sons. 
Owusu-Manu, D., Badu, E., \& Edwards, D. J. (2011). Development of a procurement management framework in Ghana: a new paradigm for interdisciplinary postgraduate education. Industry and Higher Education, 25(4), 289-305(17).

Principles for Responsible Investment. (2009). PRI Annual Report. Principles for Responsible Investment, New York. Retrieved from http://www.unpri.org/files/PRI\%20Annual\%20Report\%2009.pdf

Renneboog, L., Ter Horst, J., \& Zhang, C. (2008). Socially responsible investments: institutional aspects, performance, and investor behavior. Journal of Banking and Finance, 32, 1723-1742. http://dx.doi.org/10.1016/j.jbankfin.2007.12.039

Scholtens, B. (2009). Measuring sustainability performance of investments; the case of Dutch bond funds. Paper prepared for the PRI Academic Conference 2009. Retrieved from http://www.unpri.org/files/Scholtens_PRI2009.pdf .

Shank, T., Manullang, D., \& Hill, R. (2005). Doing well while doing good revisited: A study of Socially responsible firms short term versus long term performance. Managerial Finance, 31(8), 33-46. http://dx.doi.org/10.1108/03074350510769794

Sharpe, W. (1965). Capital asset prices: a theory of market equilibrium under conditions of risk. Journal of Finance, 19, 425-442. http://dx.doi.org/10.2307/2977928

Sharpe, W. (2007). Expected utility asset allocation. Financial Analysts Journal, 63, $18-30$. http://dx.doi.org/10.2469/faj.v63.n5.4837

Sparkes, R. (2001). Ethical investment: Whose ethics, which investment? Business Ethics: A European Review, 10(3), 194-205. http://dx.doi.org/10.1111/1467-8608.00233

Statman, M. (2005). Fair Trading. The Journal of Portfolio Management, 32(1), $76-84$. http://dx.doi.org/10.3905/jpm.2005.599504

Steinbach, M. (2001). Markowitz revisited: mean-variance models in financial portfolio analysis. Society for Industrial and Applied Mathematics Review, 43, 31-85.

Von Neumann, J., \& Morgenstern, O. (1944). Theory of games and economic behavior (Third edition). Princeton, NJ: Princeton University Press.

\section{Note}

Note 1. For instance, if you want to evaluate the ethical level of an asset - being this one expression of a business producing animal feed - the inclusion in the combination of biological ingredients as a product is considered an improvement of the index, whereas removing them is considered a worsening. 